\title{
NWC SAF convective precipitation product from MSG: A new day-time method based on cloud top physical properties
}

\author{
C. Marcos ${ }^{1}$, J. M. Sancho ${ }^{2}$ and F. J. Tapiador ${ }^{3}$ \\ ${ }^{1}$ Spanish Meteorological Agency (AEMET); Leonardo Prieto Castro, 8, 28071, Madrid \\ ${ }^{2}$ Spanish Meteorological Agency (AEMET), Territorial delegation in Andalusia, Ceuta and Melilla; Demstenes, 4, 29010 \\ Malaga \\ ${ }^{3}$ Instituto de Ciencias Ambientales, University of Castilla-La Mancha; Avda. Carlos III s/n, 45071, Toledo \\ Received: 3-XII-2014 - Accepted: 25-III-2015 - Original version
}

Correspondence to: cmarcosm@aemet.es

\begin{abstract}
Several precipitation products use radiances and reflectances obtained from the Spinning Enhanced Visible and Infrared Imager (SEVIRI) to estimate convective precipitation. The direct use of these physical quantities in precipitation algorithms is known to generate an overestimation of the precipitation area and an underestimation of the rainfall rates. In order to extenuate these issues, the most recent Satellite Application Facility on Support to Nowcasting \& Very Short Range Forecasting (NWC SAF/MSG) software package (version 2013) includes a new day-time algorithm that takes advantage of advances in cloud microphysics estimation, namely a better knowledge of Effective Radius ( $\left.R_{\text {eff }}\right)$, Cloud Optical Thickness (COT) and Water Phase. The improved algorithm, known as Convective Rainfall Rate from Cloud Physical Properties (CRPh), uses such Cloud Top Physical Properties (CPP) to estimate rainfall rates from convective clouds on a SEVIRI pixel basis (about $3 \mathrm{~km}$ at nadir). This paper presents the novelties of the new algorithm and provides both a comparison of the product with the previous versions in the NWC SAF/MSG software package, and a validation with independent ground radar data from the Spanish Radar Network operated by AEMET. Results obtained over 46 storms suggest that the CRPh provides more precise estimates than the previous algorithm, thus being more suitable for a number of quantitative applications.
\end{abstract}

Key words: Precipitation, rainfall rates, GEO satellite, nowcasting, EUMETSAT

\section{Introduction}

Heavy rain and floods can cause power cuts, economic losses, infectious diseases and even casualties, while droughts affect health and cause hunger in vast areas of the planet. Precise measurements of precipitation may help to prevent some of these societal impacts by providing both weather prediction and climate models with good quality data. Thus, rainfall and solid precipitation are the primary input to hydrological models predicting stream flow, and early warning systems for landslides benefit from a good knowledge of recent precipitation. In agriculture, irrigation scheduling is contingent upon recent and expected rainfall in the near future, especially in semiarid environments. In the realm of weather, precipitation estimates are used for nowcasting and for assimilation into global and regional mod- els, aiming to improve the forecasts. Precipitation science is thus at the crossroads of different scientific disciplines including hydrology, numerical modelling, climate change, remote sensing, and renewable energy research (Tapiador et al., 2012).

Satellite imagery supplies very useful information regarding precipitation estimation providing data over wide, sparsely populated areas including mountainous places, and also over oceans and deserts. However, most of the satellite instruments used to estimate precipitation consists of passive sensors. For precipitation estimation purposes, two types of sensors on board meteorological satellites are mainly used: infrared (IR) and visible (VIS) imagery provide information on the properties of the particles near the cloud top (Ba and Gruber, 2001; Lensky and Rosenfeld, 1997); and microwave (MW) sensors gather information on precipitation inside the 
clouds (Kidd, 1998; Kummerow et al., 2001). This means that precipitation estimation based on MW information should be, in principle, more accurate than that which uses IR information only (Tapiador et al., 2004). Moreover, algorithms taking advantage of both types of information have been developed (Joyce et al., 2004; Miller et al., 2001; Hong, 2004). Several studies have been carried out in this respect (Smith et al., 1998; Adler et al., 2001; Miller et al., 2001).

For the time being, no MW sensor is found on board a geostationary satellite, only IR and VIS measurements are taken from this kind of platform. However both spatial and temporal resolutions provided by geostationary satellites are suitable to be used for nowcasting purposes (Scofield and Kuligowski, 2003; Levizzani et al., 2001). The SEVIRI sensor, on board Meteosat Second Generation (MSG) satellites, is a line-by-line scanning radiometer that provides information in four VIS and Near Infrared (NIR) channels and eight IR channels with a baseline repeat cycle of 15 minutes. Among the VIS channels there is a High-Resolution Visible channel with $1 \mathrm{~km}$ horizontal resolution at the sub satellite point. The other channels have $3 \mathrm{~km}$ horizontal resolution at the sub satellite point.

It is very important to provide the forecasters with tools for severe weather events monitoring with a suitable spatial and temporal resolution. The Satellite Application Facility on Support to Nowcasting \& Very Short Range Forecasting (NWC SAF) project develops several products to make nowcasting tasks easier for forecasters (www.nwcsaf.org). Additionally, these products, available over vast areas, like oceans and seas, with lack of ground measurements, can be very useful, not only for operational applications, but also for research projects such as the recent Hymex campaign case studies described by Jansà et al. (2014).

The NWC SAF/MSG software package contains two products devoted to precipitation. Precipitating Clouds (PC) assigns a Probability of Precipitation (PoP) occurrence on each SEVIRI pixel (Thoss, 2013a). Convective Rainfall Rate (CRR) estimates rainfall rates on convective events, and stratiform events associated to convection, (Rodríguez and Marcos, 2013a). The algorithms, on which these products are based, currently have a different approach.

PC takes advantage of surface temperatures and of SEVIRI spectral features that have the highest correlation with precipitation, to construct a Precipitation Index (PI). According to this PI, which has been calibrated against rain gauges, a likelihood of precipitation occurrence is assigned to each SEVIRI pixel (Thoss, 2013b).

The basis of the CRR algorithm is that the higher and thicker the clouds, the higher the probability of occurrence and the intensity of precipitation. Information about cloud top height and about cloud thickness can be obtained, respectively, from the IR brightness temperature and from the VIS reflectances. Additionally, IR-WV brightness temperature difference is a useful parameter for extracting deep convective clouds with heavy rainfall. For these reasons, the CRR algorithm assigns rainfall rates to each pixel according to VIS0.6, WV6.2 and IR10.8 SEVIRI channels and some analytical functions. These functions, that have been calibrated using radar data, connect satellite radiances with rainfall rates. The influences of environmental and orographic effects on the precipitation distribution are taken into account through some corrections that use numerical weather prediction data (Rodríguez and Marcos, 2013b).

Although useful in the absence of other data, both algorithms have common problems. Both of them use SEVIRI radiances and reflectances as input which lead to an overestimation of the precipitation area as well as an underestimation of both probabilities of precipitation and rainfall rates (Thoss, 2008; Marcos and Rodríguez, 2013a).

The NWC SAF/MSG software package, in its latest version (v2013), besides these two products (PC and CRR) computed through the algorithms described, includes a new product generator that computes the same products but using a different approach: Precipitating Clouds from Cloud Physical Properties ( $\mathrm{PCPh}$ ) and Convective Rainfall Rate from Cloud Physical Properties (CRPh). These new products have the same base, taking advantage of cloud microphysical properties. Since they need solar SEVIRI channel reflectances to be computed, they are only available during the day time.

The objective of this paper is to present the CRPh as well as to show the improvements reached by it with respect to CRR. In section 2, the methodology followed to develop the CRPh algorithm is fully described. Section 3 includes the results achieved by the CRPh through both qualitative and quantitative assessments. Conclusions and future work lines are included in section 4.

\section{Methodology}

It has been observed that information on microphysics and rain processes near cloud tops can be derived from reflected IR solar radiation by the cloud tops (Knap et al., 2000). The radiative properties of a cloud can be characterized through the Effective Radius $\left(R_{e f f}\right)$ and Cloud Optical Thickness (COT).

Effective radius is the most relevant measure that indicates the possibility of occurrence of rain formation processes in observed clouds (Rosenfeld and Gutman, 1994; Lensky and Rosenfeld, 1994). The effective radius is defined as the ratio of the third to second moments of the droplet size distribution:

$R_{e f f}=\frac{\int_{0}^{\infty} N(r) r^{3} d r}{\int_{0}^{\infty} N(r) r^{2} d r}$

where $N(r)$ is the concentration of particles having radius $r$.

Both the density of scatterers per meter (cloud droplets, ice crystals, or rain droplets) and the thickness of the cloud determine the COT. The COT is related to rain occurrence since the higher COT, the higher the possibility of occurrence of rain formation processes. It is possible to retrieve COT values from SEVIRI (Roebeling et al., 2006). 

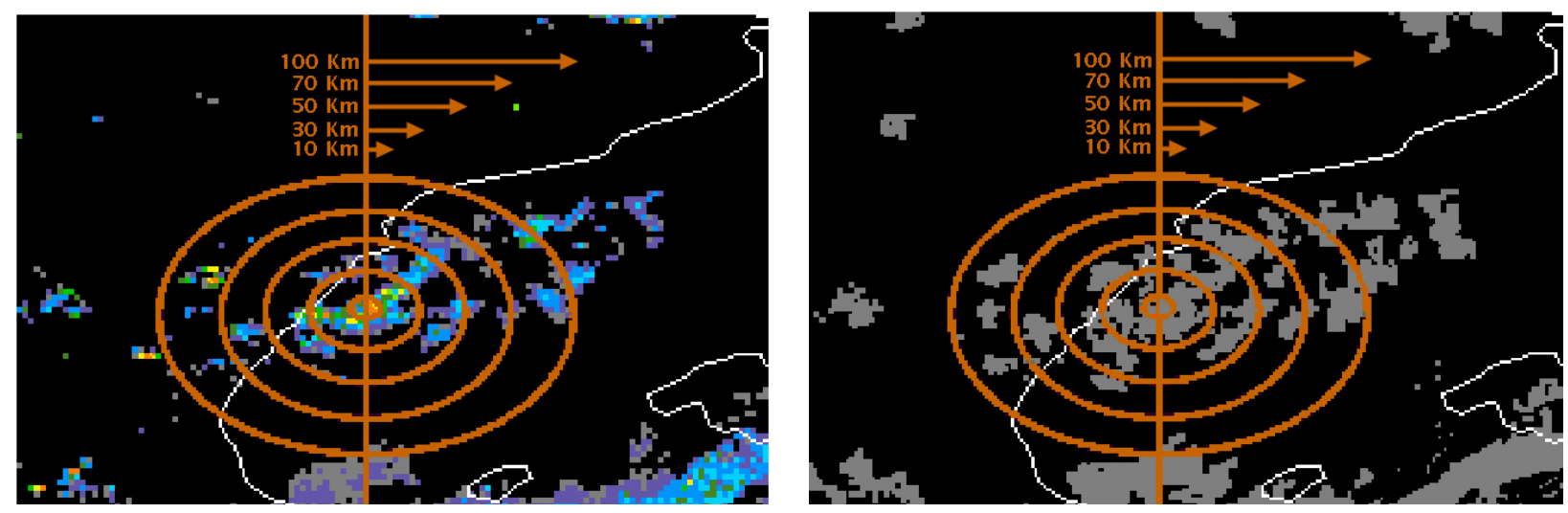

Figure 1. Comparison of radar (left) and satellite (right) precipitation estimation products in annular bins. Data corresponds to 31 st May 2009 at 12:00 UTC.

Accuracy Statistics Spain

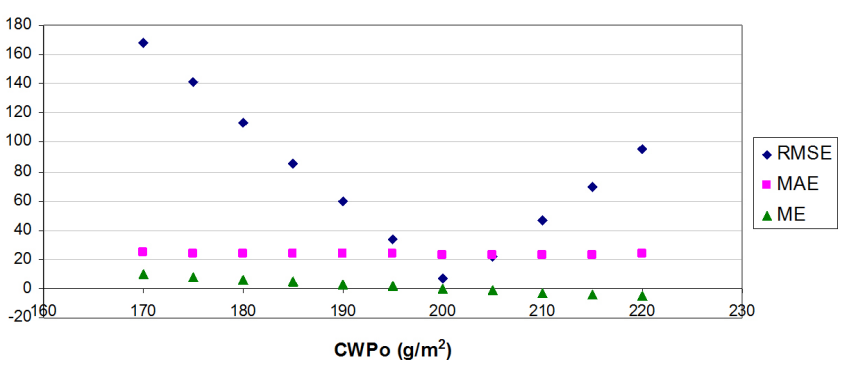

Figure 2. Accuracy statistics obtained in the comparison of number of rainy pixels in radar and satellite estimations for several CWP thresholds over Spain.

The $R_{\text {eff }}$ and the COT are computed from two SEVIRI channels, using a radiative transfer model. The cloud reflectance at VIS0.6 channel is directly related with the COT while the $R_{\text {eff }}$ is connected with the reflectance variations measured in near infrared channels like NIR1.6 (Nakajima and King, 1990).

Under certain assumptions, these two cloud top microphysical properties can be used to estimate the amount of water available to produce rain within a cloud (Roebeling and Holleman, 2009).

The $R_{\text {eff }}$ and the COT used by this algorithm are retrieved within the NWC SAF Cloud Type (CT) algorithm (Derrien, 2013).

Condensed Water Path (CWP) is computed from the $R_{e f f}$ and the COT. The CWP is the column cloud liquid water amount. This parameter is computed using the following equation (Roebeling and Holleman, 2009):

$C W P=\frac{2}{3} R_{e f f} C O T$

Several studies that connect cloud top physical properties and rain occurrence have been developed (Nauss and Kokhanovsky, 2007; Roebeling and Holleman, 2009).

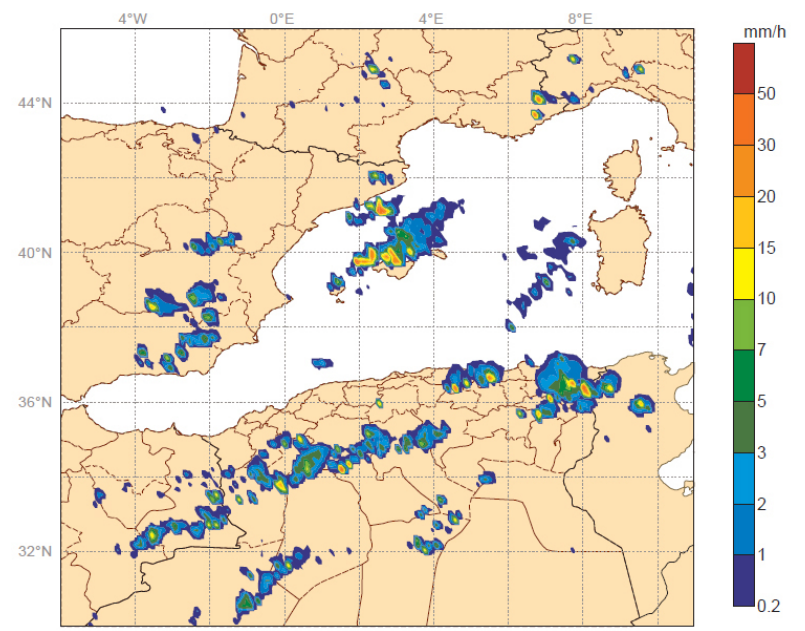

Figure 3. CRPh product over the west Mediterranean area on 26th August 2013 at 14:00 UTC. Maximum rainfall rates (in red) have no upper limit.@EUMETSAT

The $\mathrm{CRPh}$ is a nowcasting tool that provides an estimation of the instantaneous rainfall rates associated to convective clouds. Also, hourly accumulations computed by using the instantaneous rainfall rates are provided by this product.

\subsection{Datasets}

Two different types of data were used to calibrate the CRPh: radar imagery and satellite imagery.

In the case of the Spanish radar data, the composite radar data was obtained through the "optimum composite criterion" (Gutiérrez and Aguado, 2006) and contains data of 13 C-Band radars from the Spanish radar network with a scanning frequency of 10 minutes. In this case Plan Position Indicator (PPI) and Echotop radar were used. Since MSG scans over the radar area about 10 minutes later than the MSG time slot, for a time matching 0 and 20 minutes MSG slots have 

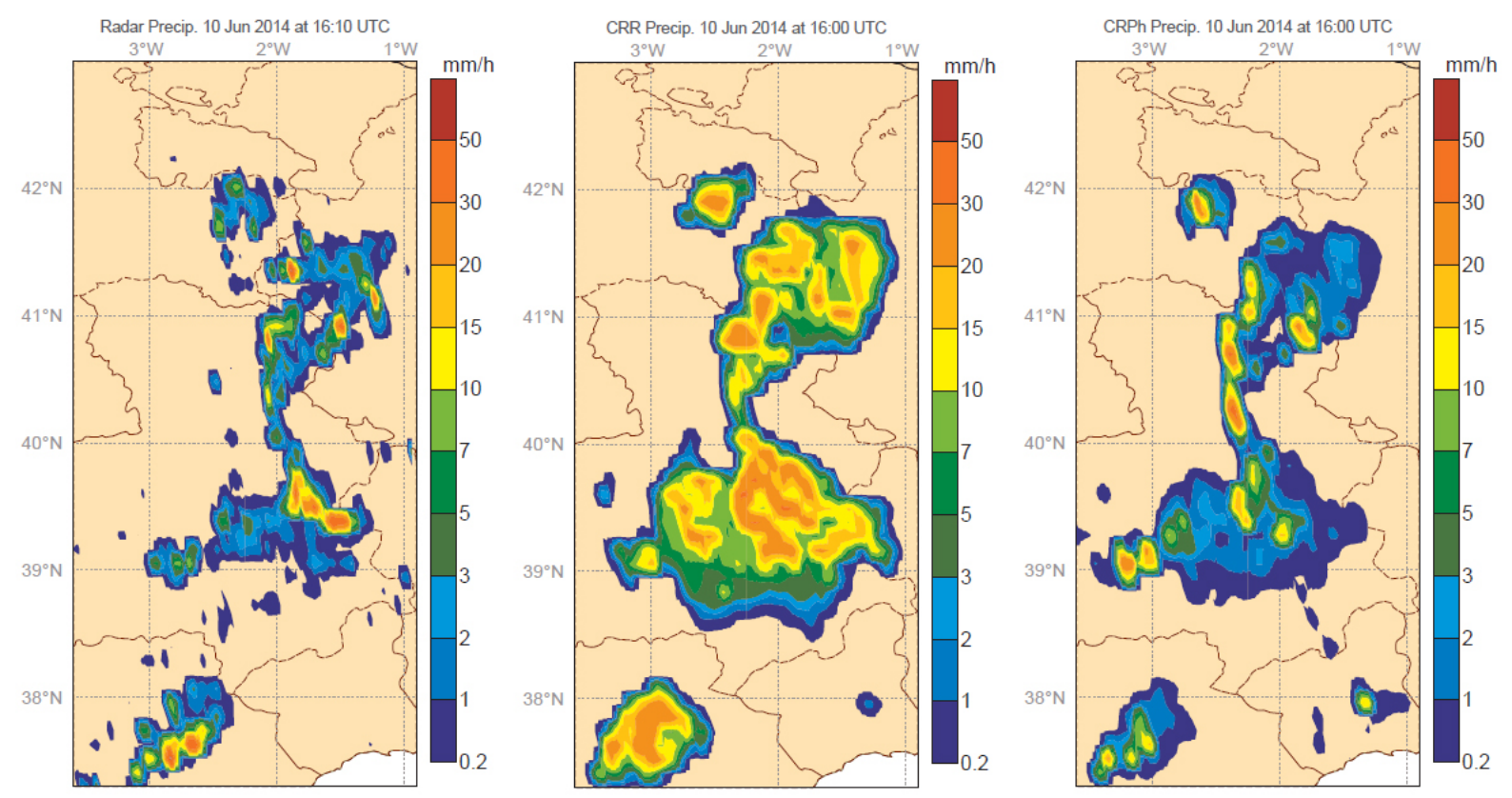

Figure 4. Precipitation rate $\left(\mathrm{mm} \mathrm{h}^{-1}\right)$ estimates from weather radar (PPI), CRR and CRPh on 10th June 2014 at 16:00 UTC. Note that slightly different nominal time products correspond to the same rainfall rate estimation time. Maximum rainfall rates (in red) have no upper limit. OEUMETSAT

been used together with 10- and 40-minutes radar images respectively.

In the case of Hungarian radar data, reflectivity in the vertical (MRV) and Echotop were used. The Hungarian radar network generates four slots every hour. Since MSG scans over Hungary about 10 minutes later than the MSG time slot, every radar slot was used matching it to the MSG time slot from 15 minutes later.

In the case of the satellite imagery phase, $R_{e f f}$ and COT were used.

For a better spatial matching between radar and satellite imagery, radar imagery was converted into MSG projection by using a bi-linear interpolation scheme. Also, the NWC SAF/MSG Parallax tool was applied to the satellite imagery.

The dataset used for the calibration of both, the precipitation area and the rainfall rates assignment, contains:

- 40 storms over Spain from May to September 2009 at 12:00 UTC

- 18 storms over Hungary from May to September 2009 from 10:00-12:00 UTC every 30 minutes

For this kind of algorithm, only SEVIRI imagery measured close to the hours of highest sun elevation were included in this calibration dataset in order to avoid errors due to poor illumination conditions.

Since only storms which occurred from May to September were used in this calibration process, a better performance of the product is expected during this period.

\subsection{Technique}

The CRPh algorithm was designed to be computed at a pixel level. For a faster computing process, rainfall rates are only estimated over the rainy area. Therefore, the CRPh is computed in two steps: first, the precipitation area is enclosed, and then, rainfall rates are assigned to each pixel inside this area.

\subsubsection{Definition of the rainy area}

According to the literature, clouds need, at least, a cloud top effective radius higher than $14 \mu \mathrm{m}$ to produce rain (Rosenfeld and Gutman, 1994) so this threshold has been accepted to detect rain clouds.

The rainy area is enclosed also taking into account a CWP threshold. To establish the CWP threshold, the number of rainy pixels were summed up in annular bins with radii from $10 \mathrm{~km}$ to $100 \mathrm{~km}$ in $10 \mathrm{~km}$ spatial intervals. The centre of the annuli was matched with the centre of the storm that was taken as the pixel with highest radar rainfall rate (see Figure 1). The number of rainy pixels included in each annulus in radar images was compared to the ones obtained in satellite images from algorithms using different CWP thresholds. The threshold to consider a radar pixel as rainy was fixed in $0.2 \mathrm{~mm} \mathrm{~h}^{-1}$. Accuracy measurements, Mean Error (ME), Mean Absolute Error (MAE) and Root Mean Square Error (RMSE), were obtained for each CWP threshold. According to the accuracy measurements obtained for each CWP for both Spanish and Hungarian radar 

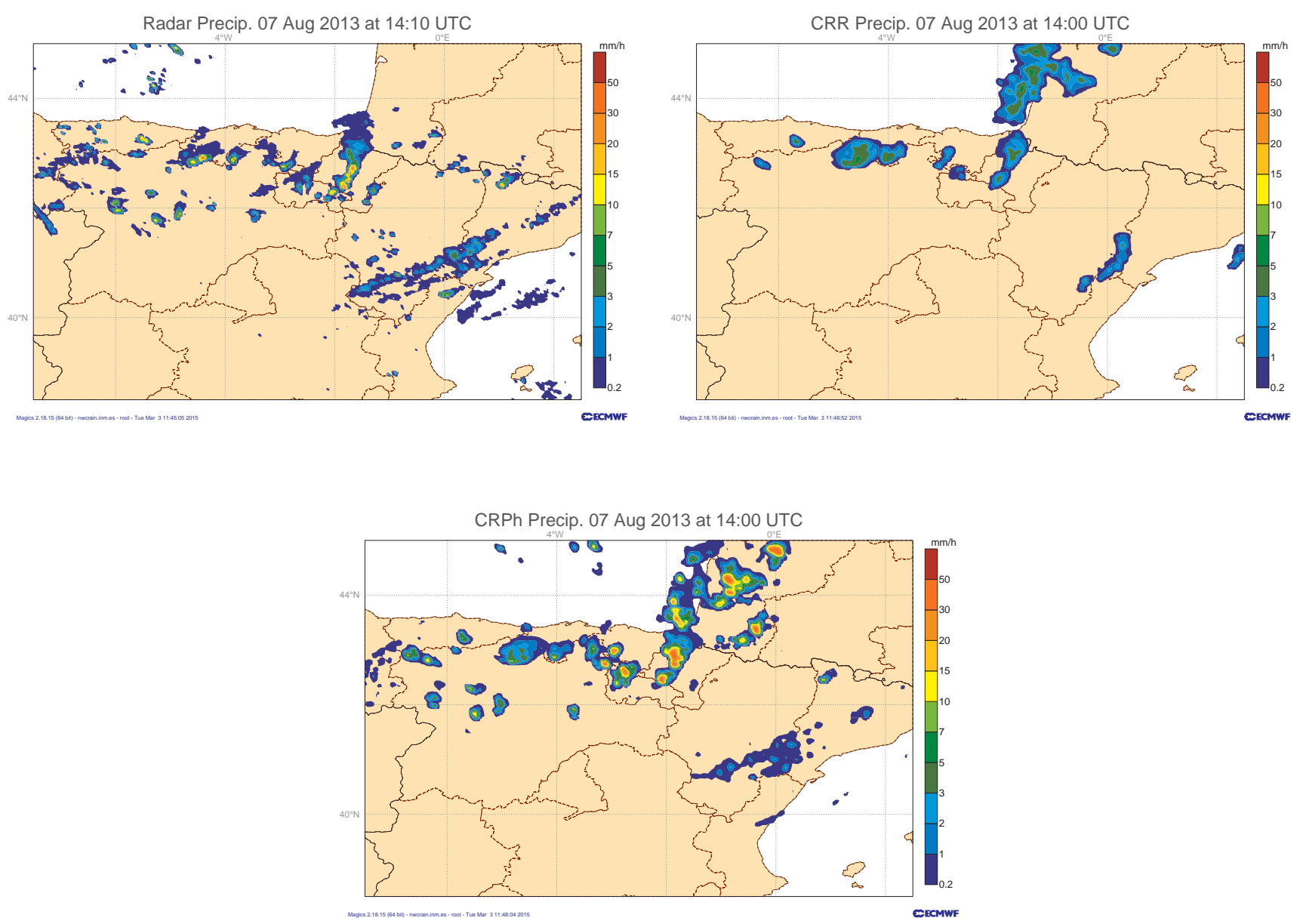

Figure 5. Precipitation rate $\left(\mathrm{mm} \mathrm{h}^{-1}\right)$ estimates from weather radar (PPI), CRR and CRPh products on 7th August 2013 at 14:00 UTC. Note that slightly different nominal time products correspond to the same rainfall rate estimation time. Maximum rainfall rates (in red) have no upper limit. OEUMETSAT

data, the most suitable threshold to enclose the rainy area is $\mathrm{CWP}_{0}=200 \mathrm{~g} \mathrm{~m}^{-2}$, since it matches with the minimum value of the RMSE and also ME changes of sign at this CWP value (see Figure 2).

\subsubsection{Assignment of the rainfall rates}

Rainfall rates are assigned to every pixel enclosed inside the rainy area depending on the CWP computed in each pixel. To find a relationship between rainfall rates and CWP, a similar calculation was done as in the case of the rainy area definition. This time the number of radar rainy pixels was summed up for different rainfall rate thresholds, and for each threshold it was compared to the number of satellite estimated rainy pixels from algorithms using different CWP thresholds. The CWP threshold algorithm with lower RMSE was selected for each radar rainfall rate threshold for both Spanish and Hungarian radar data. This way, a set of data pairs, radar rainfall rate $\mathrm{CWP}$, was obtained.
Due to the nature of the data, the rainfall rate estimation from IR radiances and VIS reflectances cannot be so accurate; therefore, trying to estimate rainfall rates higher than $50 \mathrm{~mm} \mathrm{~h}^{-1}$ using this type of data is not realistic. Therefore, a maximum limit of $50 \mathrm{~mm} \mathrm{~h}^{-1}$ was established. Then an adjustment with the radar rainfall rate - CWP data pairs was done in order to obtain the best fit function. The mathematical expression for this empirical function is the following:

$R R=50\left\{1-\exp \left[-0.5\left(\frac{C W P-155}{1700}\right)^{2}\right]\right\}$

where $R R$ are radar derived rainfall rates $\left(\mathrm{mm} \mathrm{h}^{-1}\right)$ and CWP is cloud water path $\left(\mathrm{g} \mathrm{m}^{-2}\right)$.

This way, rainfall rates are computed for each pixel detected as a rainy pixel depending on the CWP.

As an option, at this stage, the CRPh combines the precipitation pattern computed with the CRPh algorithm in the 


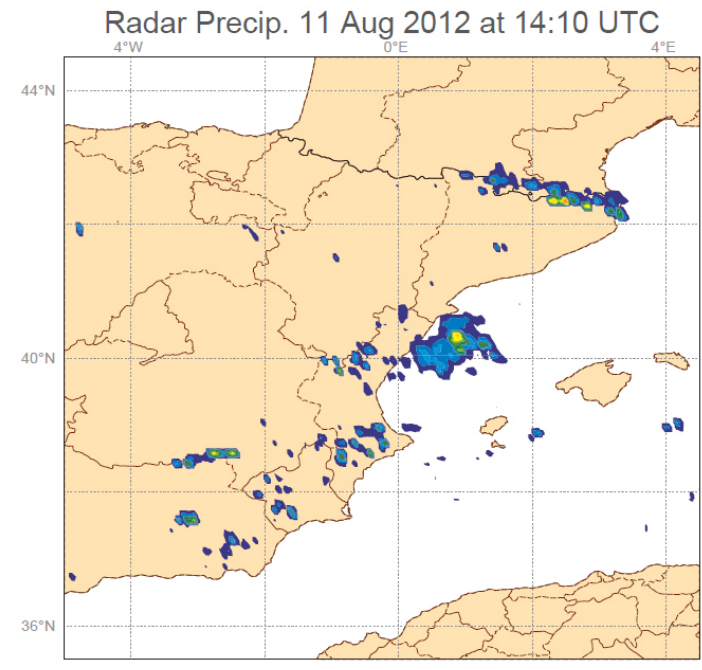

CRPh Precip. 11 Aug 2012 at 14:00 UTC

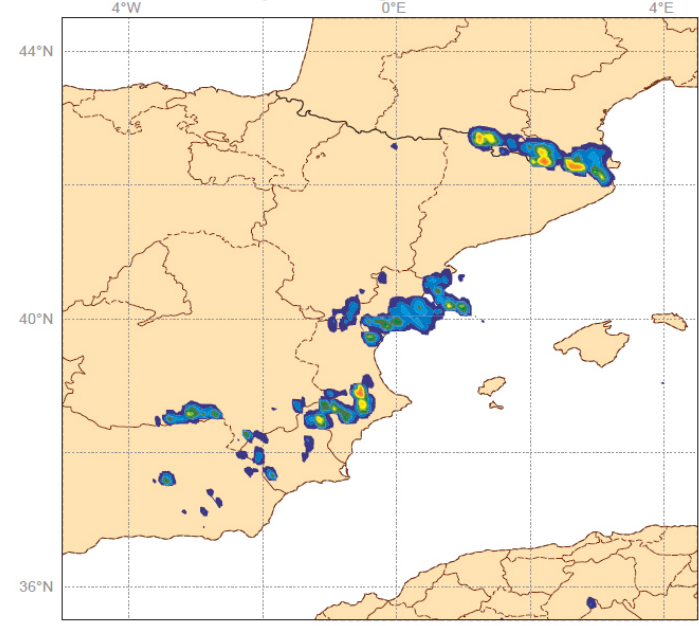

SEVIRI IR10.8 11 Aug 2012 at 14:00 UTC

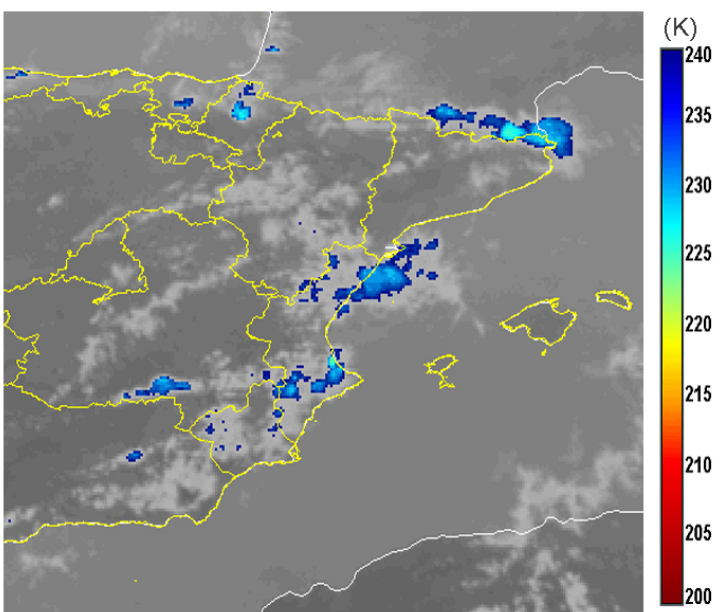

CRR Precip. 11 Aug 2012 at 14:00 UTC
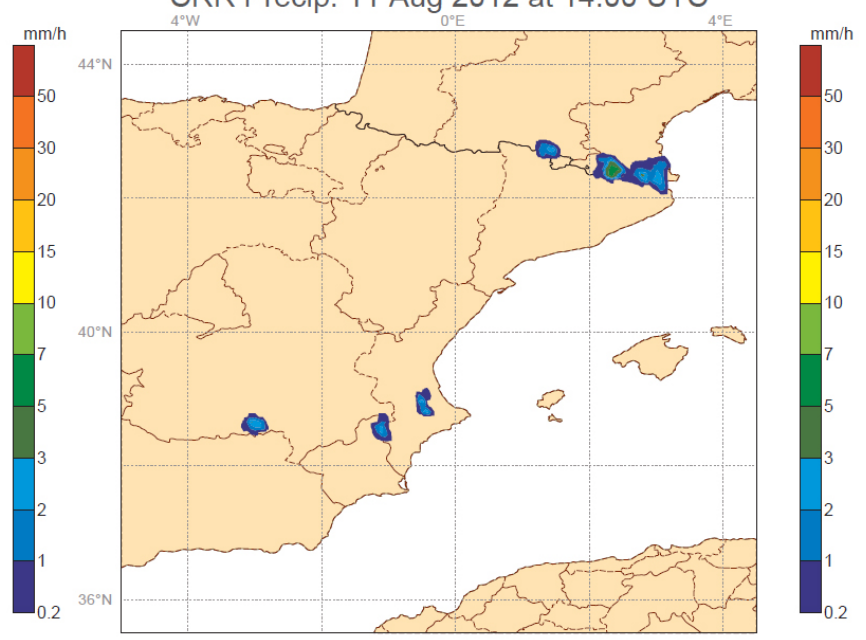

Figure 6. Precipitation rate $\left(\mathrm{mm} \mathrm{h}^{-1}\right)$ estimates from weather radar (PPI), CRR, CRPh and enhanced SEVIRI IR10.8 products on 11 th August 2012 at 14:00 UTC. Note that slightly different nominal time products correspond to the same rainfall rate estimation time. Maximum rainfall rates (in red) have no upper limit. OEUMETSAT

previous step with a precipitation pattern derived through a lightning algorithm (Marcos and Rodríguez, 2013b).

Since the inputs used by this product are highly dependant on SEVIRI solar channels, it can only be generated during day-time.

It has been observed that, under poor illumination conditions, the rainfall rates assigned by this product are erroneously high. In order to provide the user with information about the reliability of the estimated rainfall rates, an illumination quality flag (CRPh_IQF) was developed (Marcos and Rodríguez, 2013b). CRPh_IQF is included as an output of the product and it must be understood as an indicator of the confidence that a forecaster can have on the rainfall rates estimated by the product.

\section{Results and discussion}

An example of the CRPh visualization is shown in Figure 3.

The $\mathrm{CRPh}$ is designed to be used by forecasters. Besides the intensity of precipitation, it is also important to monitor the precipitation pattern as well as its evolution. In order to check all this information, both qualitative and quantitative assessments were carried out in order to compare CRR (day-time) with CRPh.

\subsection{Qualitative assessment}

A selection of convective episodes were assessed using PPI and Echotop radar products. In these cases, CRR, $\mathrm{CRPh}$ and PPI radar were compared. Figure 4 shows a representative example of this selection. 
Table 1. Results of validation through annular bin comparisons.

\begin{tabular}{|c|c|c|c|c|c|c|}
\hline \multirow{2}{*}{$\begin{array}{l}\text { Annular bin } \\
\text { radius }(\mathrm{km})\end{array}$} & \multicolumn{3}{|c|}{ Total rainfall rate in annular bins } & \multicolumn{3}{|c|}{ Rainfall rate average in annular bins } \\
\hline & $\operatorname{Radar}\left(\mathrm{mm} \mathrm{h}^{-1}\right)$ & $\mathrm{CRR}\left(\mathrm{mm} \mathrm{h}^{-1}\right)$ & $\mathrm{CRPh}\left(\mathrm{mm} \mathrm{h}^{-1}\right)$ & $\operatorname{Radar}\left(\mathrm{mm} \mathrm{h}^{-1}\right)$ & $\mathrm{CRR}\left(\mathrm{mm} \mathrm{h}^{-1}\right)$ & $\mathrm{CRPh}\left(\mathrm{mm} \mathrm{h}^{-1}\right)$ \\
\hline $0-5$ & 117.5 & 36.1 & 53.6 & 8.1 & 2.3 & 3.9 \\
\hline $5-10$ & 94.8 & 78.2 & 82.8 & 3.4 & 2.1 & 2.8 \\
\hline $10-20$ & 143.4 & 181.0 & 139.5 & 2.6 & 1.9 & 1.8 \\
\hline $20-40$ & 307.6 & 389.8 & 288.0 & 2.3 & 1.8 & 1.8 \\
\hline $40-60$ & 290.8 & 458.4 & 292.6 & 1.7 & 1.6 & 1.5 \\
\hline $60-80$ & 293.1 & 486.1 & 320.0 & 1.6 & 1.5 & 1.4 \\
\hline $80-100$ & 299.1 & 450.6 & 314.1 & 1.5 & 1.4 & 1.3 \\
\hline $100-150$ & 763.3 & 1014.7 & 810.6 & 1.6 & 1.6 & 1.3 \\
\hline $150-200$ & 582.0 & 892.7 & 699.4 & 1.3 & 1.4 & 1.3 \\
\hline
\end{tabular}

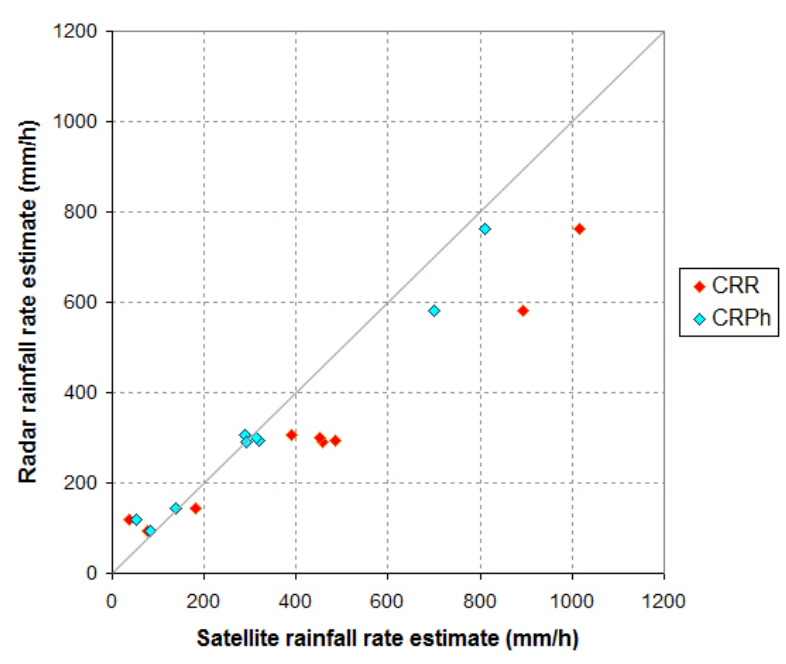

Figure 7. Comparison of total rainfall rates in different annular bins.

Since the CRR (day-time) algorithm uses IR and VIS radiance and reflectances as input, the estimated precipitation areas are very similar to the cloud tops (see Figure 4). The overall behaviour of CRR is an overestimation of the precipitation area and an underestimation of the higher rain intensities (see Figure 5). The visual comparison shows that both problems are improved in the CRPh algorithm. Under good illumination conditions, the $\mathrm{CRPh}$ estimates rain intensities closer to the radar ones than the ones estimated by the CRR. Also smaller convective nuclei and rainy areas with very low rain intensities are detected by the CRPh (see Figure 5).

Under poor illumination conditions, the CRPh overestimates rain intensities above all in the convective nuclei with higher precipitation intensities according to the radar. Nevertheless, rainy areas are better adjusted to the radar ones in the $\mathrm{CRPh}$, even with poor illumination conditions and so, under these conditions, valuable information can still be provided by the algorithm.

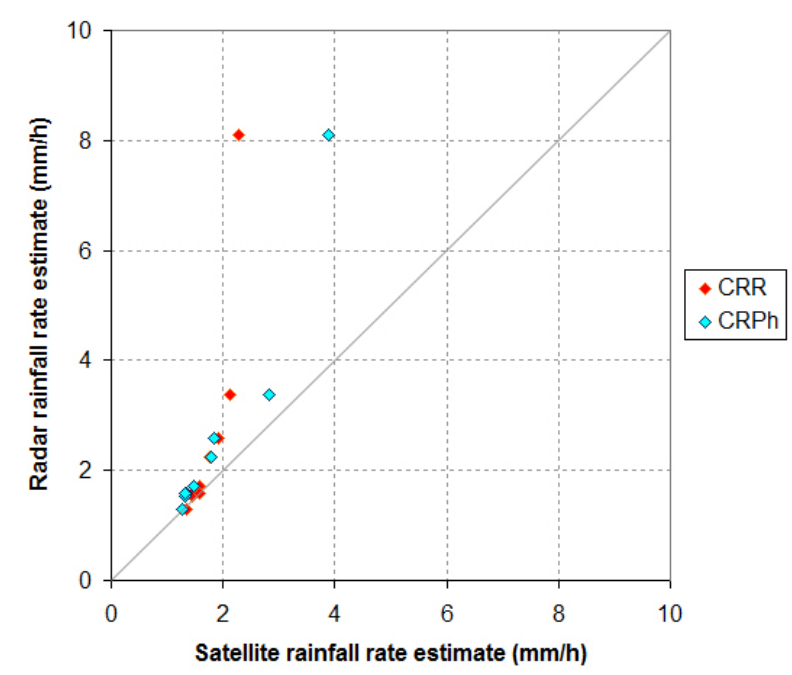

Figure 8. Comparison of averaged rainfall rates in different annular bins.

Cold ring shapes showed in enhanced IR imagery were also found in the CRR precipitation patterns. This problem is avoided in the CRPh algorithm.

The misdetection of rainfall rates associated to warm top clouds is a known weakness of IR based algorithms like the CRR. Since the CRPh algorithm does not have a high dependence on IR brightness temperature this problem is avoided (see Figure 6).

\subsection{Quantitative assessment}

An extended validation over 78 days with convective events was carried out throughout 2008 (Marcos and Rodríguez, 2013a, 2013c). This was a deterministic validation using statistical parameters like probability of detection (POD), false alarm ratio (FAR), critical success index (CSI) and percentage of corrects (PC). In this type of traditional validation, small spatial and timing matching errors can produce big errors in statistical scores (Anthes, 1983). This is known as the double penalty problem. These vali- 
dation methods are known to be not the best approaches to validate rainfall rates estimations.

A different method to verify rain detection results has been carried out in this work. A similar method to the one used in the calibration process was used.

\subsubsection{Validation procedure}

Rainfall rates were summed up in annular bins with radii from $10 \mathrm{~km}$ to $200 \mathrm{~km}$ at different spatial intervals (see Table 1) for both radar and satellite estimations (see Figure 1) in the same way as was done for the calibration process. Two types of charts were obtained. On the one hand, total precipitation estimated inside each annular bin was compared. On the other hand, rainfall rate averages, that is, total precipitation divided by number of rainy pixels inside each annular bin, were also compared.

\subsubsection{Datasets}

Dataset used for this validation contained 46 storms which occurred over Spain from May to September 2008. For each storm, data from 10:00 to 14:00 UTC every $30 \mathrm{~min}$ utes were used. The CRR and the CRPh were compared to the Radar PPI from the Spanish Radar network. Both spatial and time matching were done in the same way as in the calibration process (Section 2.1).

\subsubsection{Results}

Result of both types of comparisons can be seen in Table 1. Also, Figure 7 and Figure 8 summarize these results.

The comparison of total rainfall rates in annular bins (Figure 7) shows a good agreement between both satellite products and radar, above all for the intermediate distance bins, from $5-10 \mathrm{~km}$ to $80-100 \mathrm{~km}$. Looking at the farthest annular bins from the centre of the storm, an overestimation of the CRR rainfall rate estimations can be observed. In this case, the CRPh performs clearly better than the CRR, showing total precipitation estimations very close to the radar ones. Also, both satellite products show an underestimation at the closest annular bin to the centre of the storm, more so in the CRR than in the CRPh.

The comparison of averaged rainfall rates shows (Figure 8) a good agreement of both the CRR and the CRPh on all annular bins except for the closest one to the centre of the storm.

\section{Conclusions}

Given the information provided in the previous section, it is easy to conclude that NWC SAF convective precipitation estimations have been improved by using cloud top microphysical information. Qualitative validation showed that the $\mathrm{CRPh}$ provides better adjusted precipitation areas according to the radar in relation to the CRR. The CRR problem with respect to the high dependence on IR brightness temperature disappeared with the CRPh: warm top rainy clouds are detected and cold ring signals do not appear as precipitation patterns. The $\mathrm{CRPh}$ rainfall rates under good illumination conditions are more accurate than the CRR ones, however an overestimation appears under poor illumination conditions.

According to quantitative validation there is an underestimation of the pixels that reach the highest rainfall rates although there is an improvement of the $\mathrm{CRPh}$ with respect to the CRR. This happens because, at the same time, satellite precipitation estimations are lower than the radar ones and also, the pixels with the highest rainfall rates are not placed in the same pixel. This shows that satellite estimations do not place precipitation exactly in the same area as radar does, but the distribution of precipitation can be similar according to the rest of the points that shows results closer to the radar ones. The total rainfall rate at a distance greater than $100 \mathrm{~km}$ from the centre of the storm is overestimated by the CRR while the $\mathrm{CRPh}$ shows good behaviour. However, averaged rainfall rates at the same distances are in good agreement with radar rainfall rates. This issue can be explained by the phenomenon also detected along the qualitative validation: the CRR shows more widespread rainy areas with lower rainfall rates, being the total amount of precipitation better estimated. The $\mathrm{CRPh}$ rainfall rate estimates are more similar to those derived from weather radar, both from the point of view of spatial distribution as well as intensity. These results are in agreement with the quantitative studies presented in the validation reports for both the CRR and the CRPh products (Marcos and Rodríguez, 2013a, 2013c) where an improvement of $26.9 \%$ in POD was reached by the CRPh with respect to the CRR. In addition, the FAR was also improved by $2.9 \%$ for the CRPh.

The main restriction is that the new algorithm needs solar reflectances to work. Maximum convection activity tends to be in the afternoon. Also severe events can take place during the night. Depending on the time of the year, afternoon storms can be detected by the CRPh algorithm but under poor illumination conditions. In these cases, the estimated intensities are not reliable, however the forecaster can still get some valuable information since it has been proven that precipitation areas are well detected. Future work includes completing this algorithm to be able to work during twilight and at night-time.

Acknowledgements. This work was part of the EUMETSAT funded Satellite Application Facility on Support to Nowcasting and Very Short-Range Forecasting project. In this framework, the Hungarian Meteorological Service kindly provided the radar data used in this study.

\section{References}

Adler, R., Kidd, C., and Petty, G., 2001: Intercomparison of global precipitation products: The third Precipitation Intercomparison Project (PIP-3), Bull Amer Meteorol Soc, 82, 1147-1167.

Anthes, R. A., 1983: Regional models of the atmosphere in middle latitudes, Mon Weather Rev, 111, 1306-1335. 
Ba, M. and Gruber, A., 2001: GOES multispectral rainfall algorithm (GMSRA), J Appl Meteorol, 40, 1500-1514.

Derrien, M., 2013: Algorithm Theoretical Basis Document for "Cloud Products" (CMa-PGE01 v3.2, CT-PGE02 v2.2 \& CTTHPGE03 v2.2), Available at www.nwcsaf.org, 87 pgs.

Gutiérrez, J. M. and Aguado, F., 2006: Quality image for the Spanish National Radar Composition, Proceedings of the 4th European Conference on Radar in Meteorology and Hydrology, Barcelona, 18-22 September 2006.

Hong, Y., 2004: Precipitation Estimation from Remotely Sensed Imagery using Artificial Neural Network-Cloud Classification System, J Appl Meteorol, 43, 1834-1853.

Jansà, A., Campins, J., Picornell, M. A., and Guijarro, J. A., 2014: Heavy rain and strong wind events over Spain during HyMeX SOP1, Tethys, 11, 25-38, doi: 10.3369/tethys.2014.11.03.

Joyce, R., Janowiak, J., Arkin, P., and Xie, P., 2004: CMORPH: A method that produces global precipitation estimates from passive microwave and infrared data at high spatial and temporal resolution, J Hydrometeor, 5, 487-503.

Kidd, C., 1998: On rainfall retrieval using polarization-corrected temperatures, Int J Remote Sens, 19, 981-996.

Knap, W. H., Stammes, P., and Koelemeijer, R. B. A., 2000: Discriminating between water and ice clouds using near-infrared AVIRIS measurements, Proceedings of the 9th AVIRIS Earth Science and Applications Workshop, NASA Jet Propulsion Laboratory, Pasadena, USA, 23-25 February 2000.

Kummerow, C., Hong, Y., Olson, W., and Yang, S., 2001: The evolution of the Goddard profiling algorithm (GPROF) for rainfall estimation from passive microwave sensors, J Appl Meteorol, 40, 1801-1820.

Lensky, I. and Rosenfeld, D., 1997: Estimation of precipitation area and rain intensity based on the microphysical properties retrieved from NOAA AVHRR data, J Appl Meteorol, 36, 234-242.

Lensky, I. and Rosenfeld, D., 2006: The time-space exchangeability of satellite retrieved relations between cloud top temperature and particle effective radius, Atmos Chem Phys, 6, 2887-2894.

Levizzani, V., Schmetz, J., Lutz, H. J., Kerkmann, J., Alberoni, P. P., and Cervino, M., 2001: Precipitation estimations from geostationary orbit and prospects for METEOSAT Second Generation, Meteorol Appl, 8, 23-41, doi: 10.1017/S1350482701001 037.

Marcos, C. and Rodríguez, A., 2013a: Validation Report for "Convective Rainfall Rate" (CRR-PGE05 v4.0), Available at www. nwcsaf.org, 21 pgs.

Marcos, C. and Rodríguez, A., 2013b: Algorithm Theoretical Basis Document for "Precipitation products from Cloud Physical Properties" (PPh-PGE14: PCPh v1.0 \& CRPh v1.0), Available at www.nwcsaf.org, 40 pgs.

Marcos, C. and Rodríguez, A., 2013c: Validation Report for "Precipitation products from Cloud Physical Properties" (PPhPGE14: PCPh v1.0 \& CRPh v1.0), Available at www.nwcsaf. org, 26 pgs.

Miller, S. W., Arkin, P. A., and Joyce, R., 2001: A combined microwave/infrared rain rate algorithm, Int J Remote Sens, 22, 3285-3307, doi: 10.1080/01431160152609 155.

Nakajima, T. and King, M., 1990: Determination of the optical thickness and effective particle radius of clouds from reflected solar radiation measurements. Part I: Theory, J Atmos Sci, 42, 1878-1893.

Nauss, T. and Kokhanovsky, A. A., 2007: Advances in Geosciences Assignment of rainfall confidence values using multispectral satellite data at mid-latitudes: first results, Advances in
Geosciences, 10, 99-102.

Rodríguez, A. and Marcos, C., 2013a: Product User Manual for the "Convective Rainfall Rate" (CRR - PGE05 v4.0), Available at www.nwcsaf.org, 28 pgs.

Rodríguez, A. and Marcos, C., 2013b: Algorithm Theoretical Basis Document for "Convective Rainfall Rate" (CRR-PGE05 v4.0), Available at www.nwcsaf.org, 36 pgs.

Roebeling, R. and Holleman, I., 2009: SEVIRI rainfall retrieval and validation using weather radar observations, J Geophys Res, 114, D21 202, doi: 10.1029/2009JD012 102.

Roebeling, R., Feijt, A. J., and Stammes, P., 2006: Cloud property retrievals for climate monitoring: Implications of differences between Spinning Enhanced Visible and Infrared Imager (SEVIRI) on METEOSAT-8 and Advanced Very High Resolution Radiometer (AVHRR) on NOAA-17, J Geophys Res, 111, D20 210, doi: 10.1029/2005JD006 990.

Rosenfeld, D. and Gutman, G., 1994: Retrieving microphysical properties near the tops of potential rain clouds by multispectral analysis of AVHRR data, Atmos Res, 34, 259-283.

Scofield, R. and Kuligowski, R., 2003: Status and outlook of operational satellite precipitation algorithms for extreme-precipitation events, Weather Forecast, 18, 1037-1051.

Smith, E. A., Lamm, J. E., Adler, R., Alishouse, J., Aonashi, K., Barrett, E., Bauer, P., Berg, W., Chang, A., Ferraro, R., Ferriday, J., Goodman, S., Grody, N., Kidd, C., Kniveton, D., Kummerow, C., Liu, G., Marzano, F., Mugnai, A., Olson, W., Petty, G., Shibata, A., Spencer, R., Wentz, F., Wilheit, T., and Zipser, E., 1998: Results of WetNet PIP-2 project, J Atmos Sci, 55, 1483-1536.

Tapiador, F. J., Kidd, C., Levizzani, V., and Marzano, F. S., 2004: A maximum entropy approach to satellite quantitative precipitation estimation (QPE), Int J Remote Sens, 25, 4629-4639, doi: 10.1080/01431160410001710000.

Tapiador, F. J., Turk, J., Petersen, W., Hou, A., García-Ortega, E., Machado, L., Angelis, C., Salio, P., Kidd, C., Huffman, G., and Castro, M., 2012: Global precipitation measurement: Methods, datasets and applications, Atmos Res, 104-105, 7097, doi:10.1016/j.atmosres.2011.10.021.

Thoss, A., 2008: Validation Report for "Precipitating Clouds" (PCPGE04 v1.4), Available at www.nwcsaf.org, 29 pgs.

Thoss, A., 2013a: Product User Manual for SAFNWC/MSG "Precipitating Cloud" (PC-PGE04 v1.5), Available at www.nwcsaf. org, 18 pgs.

Thoss, A., 2013b: Algorithm Theoretical Basis Document for SAFNWC/MSG "Precipitating Cloud" (PC-PGE04 v1.5), Available at www.nwcsaf.org, 21 pgs. 